\title{
Case Studies of Comparing EN 954-1 and EN ISO 13849-1 Standard for Design of Industrial Machinery Safety Control System
}

\author{
Tae-Ho Kim ${ }^{1}$, Hong-Ki Kim ${ }^{2}$, Hoon Yong Yoon ${ }^{3}$ \\ ${ }^{1}$ Green Safety, Busan, 618-820 \\ ${ }^{2}$ Department of Industrial and Management Engineering, Kyonggi University, Suwon, 443-760 \\ ${ }^{3}$ Department of Industrial and Management Systems Engineering, Dong-A University, Busan, 604-714
}

\begin{abstract}
Objective: The aim of this study was to compare old standard EN 954-1 and new standard EN ISO 13849-1 through case study and provide necessity of adaptation of EN ISO 13849-1 in Korea. Background: International and EU harmonized standard EN ISO 13849 "safety of machinery - Safety-related parts of control system" is classified into Part 1: General principles for design and Part 2: Validation. EN ISO 13849-1 standard was introduced in Official Journal of the European Union on September 8, 2009 as harmonized standard, and old standard EN 954-1 was withdrawn on December 31, 2011. So, EU decided to use of EN ISO 13849-1 standard forcibly from January 1, 2012 for safety of machinery. New machines need to be CE marked if they are to be placed on the market in the European Economic Area(EEA), Switzerland or Turkey, and Korean machine builder should apply EN ISO 3849-1 standard for safety of machinery accordingly. However, current Korean Safety Certification system(KCs mark) for dangerous machinery is not referred to EN ISO 13849-1 standard as safety standard. There is a need of research for adaptation of EN ISO 13849-1 standard in Korea as safety standards for new design of safety-related control system which use mostly electronic components. Method: Five case studies of representative designs for safety-related control system in accordance with EN 954-1were selected according to safety category from B to 4. And these five representative designs were tried to change new design in accordance with EN ISO 13849-1 standard. The results of comparison were analyzed in aspect of economy and technical complexity. Results: The results showed that EN ISO 13849-1 provided quantitative method of application and it enabled designers to create safety-related control systems that require fewer components and less wiring, with many of the components being to a lower specification and, therefore, less costly. Conclusion: EN ISO 13849-1 standard is good for electronic safety-related control systems compare to EN 954-1. By considering the importance of application of EN ISO 13849-1 and benefits, the application of EN ISO 13849-1 as safety standard for safety of machinery is urgent in Korea. Application: The results of comparing EN 954-1 and EN ISO 13849-1 standard might help to determine the adaptation of EN ISO 13849-1 standard for safety of industrial machinery in Korea.
\end{abstract}

Keywords: EN 954-1, EN ISO 13849-1, Safety Category, Risk graph, Safety-related parts of control system

Corresponding Author: Hoon Yong Yoon. Department of Industrial and Management Systems Engineering, Dong-A University, Busan, $604-714$. Phone: +82-51-200-7691, E-mail: yhyoon@dau.ac.kr Copyright@2013 by Ergonomics Society of Korea(pISSN:1229-1684 eISSN:2093-8462). All right reserved.

(c) This is an open-access article distributed under the terms of the Creative Commons Attribution Non-Commercial License(http://creativecommons.org/licenses/by-nc/3.0/), which permits unrestricted non-commercial use, distribution, and reproduction in any medium, provided the original work is properly cited. http://www.esk.or.kr 


\section{Introduction}

국제 및 유럽 표준 EN ISO 13849는 "Safety of Machinery - Safety-Related Parts of Control Systems" 에 관한 표준 규격이며, Part 1 "General Principles for Design"과 Part 2 "Validation"으로 구분된다. 이는 기계 안 전 분야에서 제어시스템의 안전 부품 관련, 제 1 부 설계 지침 과 제 2 부 검증 부분으로 나뉜다.

현재 유럽연합(EU)은 2009년 9월 8일 처음 Official Journal of the European Union에 EN ISO 13849 규격이 조화 규격 Harmonized Standard)으로 지정된 이후, 2012 년 1월 1일부터 기존의 $\mathrm{EN} \mathrm{954-1} \mathrm{규격의} \mathrm{적용을} \mathrm{중단하}$ 고 EN ISO 13849 규격의 적용을 강제화하였다(European Commission, 2012).

이는 2011년 12월 31일 이후 유럽연합(EU) 역내로 수 입 또는 역내에서 유통되는 산업기계류는 유럽연합(EU) 기 계 지침(Machinery Directive, 2006/42/EC)에 의해 제조 자는 $\mathrm{EN} \mathrm{ISO} 13849$ 규격을 적용하여 관련 적합성을 입증 하여야 한다는 의미이다. 이에 대해 국내의 부품 및 산업기 계류 제조자는 유럽 수출 시 해당 요건들을 검토하고 준비 를 하여야 한다. 또한 국내 산업기계류 안전인증 제도(KCs 마크) 하에서도 국제표준 ISO 13849 규격의 도입과 연구가 필요한 현실이다.

국제 학술지 JOSE(International Journal of Occupational Safety and Ergonomics)에 보고된 기계 제어시스템의 비 정상적인 기능에 의한 사고 분석 (Dźwiarek, 2004)에 따르 면, 1996년에서 2002년 사이에 폴란드에서 발생된 사고 중 설문조사에 응한 700 건의 사고를 분석한 결과 아래의 Figure 1, Figure 2, Figure 3과 같은 결과를 얻었다.

Figure 1 의 경우, 기계에서 일어난 모든 사고 중 비정상적 인 제어시스템의 동작에 의한 사고 건수를 보여주는데, 기계 의 제어시스템 관련 오작동에 의한 사고가 비중이 높음을 알 수 있다.

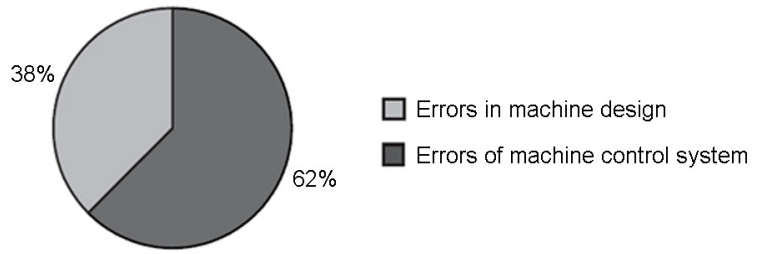

Figure 1. Accident caused by improper functioning of the control system in relation to all accidents at machine

(Dźwiarek, 2004)
Figure 2에서는 사고의 심각성에 따라 분류된 결과로 기 계의 제어시스템의 오작동이 중대 사고에 더 영향을 미치는 경향을 확인할 수 있다. 마지막으로 Figure 3의 경우 사고 요인 별 빈도를 나타내었다. 가장 많은 $58 \%$ 를 차지하는 부 분은 안전 기능의 부재를 의미하는데, 기계의 위험 요소에 적절한 보호장치를 설계하지 않은 경우이다. 그 다음은 $26 \%$ 를 차지한 제어시스템의 안전카테고리(Safety Category) 요건을 충족하지 못한 경우이다. 나머지는 잘못된 안전 기 능(Safety Function)의 정의와 컨트롤러의 소프트웨어 에러, 사용 환경에 부합하지 않은 부품의 사용이 나타났다.

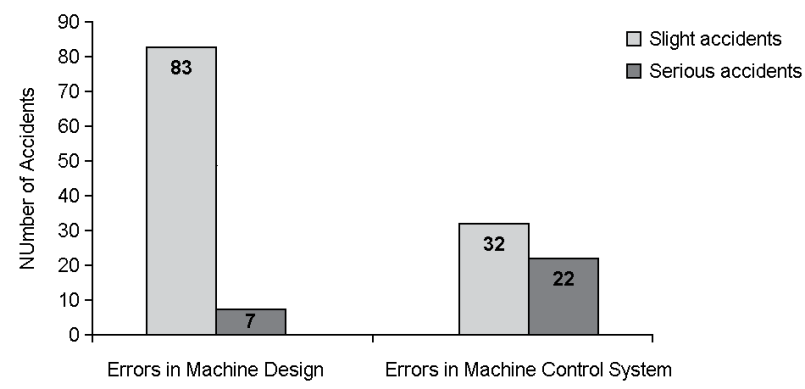

Figure 2. Severity of accidents(Dźwiarek, 2004)
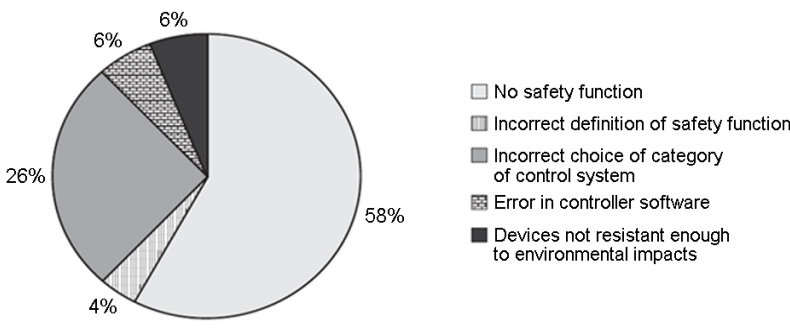

Figure 3. Frequency of different cause of accidents caused by improper functioning of the control system(Dźwiarek, 2004)

여기서 주목할 것은 최초 기계 설계자가 이러한 문제들을 미리 대처하고 설계를 하였다면 미리 막을 수 있는 사고라는 것이다. 즉 관리가 가능한 사고이다. 인용된 보고서의 결과 가 국내 환경과 유사한지 또는 정확한 결과치인지의 논의를 떠나 기계 제어장치의 비정상적 기능에 의한 사고가 어느 정도의 비중이 있고, 이러한 사고는 설계 지침에 대한 표준 에 따라 설계가 된다면 사전에 관리가 가능한 것이기 때문 에 국내에서도 이에 대한 연구가 필요하다.

또한, 이미 2013년 3월 1일부로 적용되는 기계류의 자율 안전확인신고(산업안전보건법 제35조) 제도가 시행됨에 따 라 국내 제조자 또는 수입하는 자는 안전보건공단으로부터 
자율안전확인신고증명서를 발급 받아야 한다. 자율안전신고 제도란, 자율안전확인 대상 기계·기구 등을 제조(설치하거 나 주요 구조 부분을 변경하는 경우를 포함)하거나 수입하 는 자가 해당 제품의 안전에 관한 성능이 자율안전 기준에 맞는지 확인하여 고용노동부장관에게 신고하는 제도이며, 해 당 제조자 또는 수입자는 반드시 위험성 평가 자료 등을 제 출하여야 하는 의무가 있다. 따라서, 제어시스템의 오동작에 따른 위험성을 최소화 혹은 제거하기 위한 국내 안전 기준의 검토와 향후 방향에 대한 연구가 필요하다.

\section{Objective and Method}

본 연구의 목적은 EN 954-1과 EN ISO 13849-1 규격 을 이론적으로 고찰하고, 문헌연구를 통해 기존 연구들을 확 인하여, 실제 설계된 기계 제어 관련 시스템을 $\mathrm{EN} \mathrm{954-1}$ 과 EN ISO 13849-1 규격을 적용하여 서로 비교 분석하고 자 하였다.

비교 분석은 실제 업체에서 설계한 회로를 바탕으로 5 가 지 예를 들어 실시하였다. 이 5가지는 각 위험성 추정에 사 용된 리스크 그래프(Risk Graph) 방식에 의해 분류되어 $\mathrm{EN} \mathrm{954-1에서} \mathrm{사용된} \mathrm{안전카테고리} \mathrm{등급} \mathrm{B}, 1,2,3,4$ 와 EN ISO 13849-1에서 사용된 성능 수준(PL, Performance Level) a, b, c, d, e의 수준을 같은 결과의 위험성 추정 단계 에서 각각 비교하기 위함이다. 회로의 선택은 이 전에 $\mathrm{EN}$ 954-1을 적용하여 해외 인증기관의 검사와 인증을 받은 산 업기계를 대상으로 하고, EN 954-1에 의해 분류된 안전카 테고리 등급 $\mathrm{B}, 1,2,3,4$ 의 각 회로 5 가지를 선택하여 대표 화 하였다. 여기서 각 회로를 새롭게 EN ISO 13849-1을 적용할 경우 달라지는 점을 확인하기 위함이다. 아울러 그 차이를 기술적인 관점과 경제적인 관점에서 비교 분석함으 로써 제조자의 이해를 돕고 국내의 대응 방향을 제시하였다.

오늘날 안전 관련 시스템의 설계에 있어 전자 부품 (Electronic Component)이나, 프로그램 가능 전자시스템 (Programmable Electronic System)의 사용 증가 및 회로 의 복잡성(Complexity) 때문에 제어시스템의 설계에 있어 확률 이론(Probability Theory)을 도입하게 되었다. 이것 이 EN ISO 13849 규격의 제정 배경이며, 이러한 접근은 각 안전 제어시스템이나 회로에 사용된 부품의 고장 확률 (Probability of Failure of Component) 고찰이라는 IEC 61508 규격에서 이미 도입된 사항이다. 이러한 기능 안전 (Functional Safety)의 관점에서 볼 때 각 산업 별로 많은 표준들이 있는데, 본 연구에서는 산업기계 관련 부문 중 관 련되는 EN ISO 13849 규격을 연구 범위로 한다. 특히 IEC
62061 규격은 산업기계 관련 부문이나 SRECS (SafetyRelated Electrical Control System), 즉 안전 관련 전기 제어시스템에 국한 됨으로 유압 및 공압 제어회로를 포함하 는 보다 넓은 범위의 EN ISO 13849 규격을 본 연구에서는 연구 범위로 하였다.

\section{Major Key points of EN ISO 13849-1}

\subsection{Risk Estimation}

먼저 산업기계에 해당되는 위험성은 아래와 같다.

- 기계적 상해 위험: (예) 충돌, 비래, 협착, 절단, 끼임, 말 림, 찰과상, 추락 등

- 전기적 위험: (예) 화상, 화재, 감전 등

- 열적 위험: (예) 화상, 탈수, 동상, 화재 등

-소음 위험: (예) 통증, 영구적 청력손실, 스트레스, 이명, 피로 등

- 진동 위험: (예) 통증, 신경학적 장애, 관절질환 등

- 방사선 위험: (예) 화상, 눈 또는 피부 손상, 우전적 변 이 등

- 물질/재료에 의한 위험: (예) 호흡곤란, 질식, 암, 부식, 폭발, 화재 등

- 인간공학적 설계 원칙 무시: (예) 통증, 피로, 근골격계 질환, 스트레스, Human error 등

이러한 산업기계의 노출된 위험성을 추정하기 위해서 주 로 리스크 그래프 방식이 사용된다. EN ISO 13849-1 규

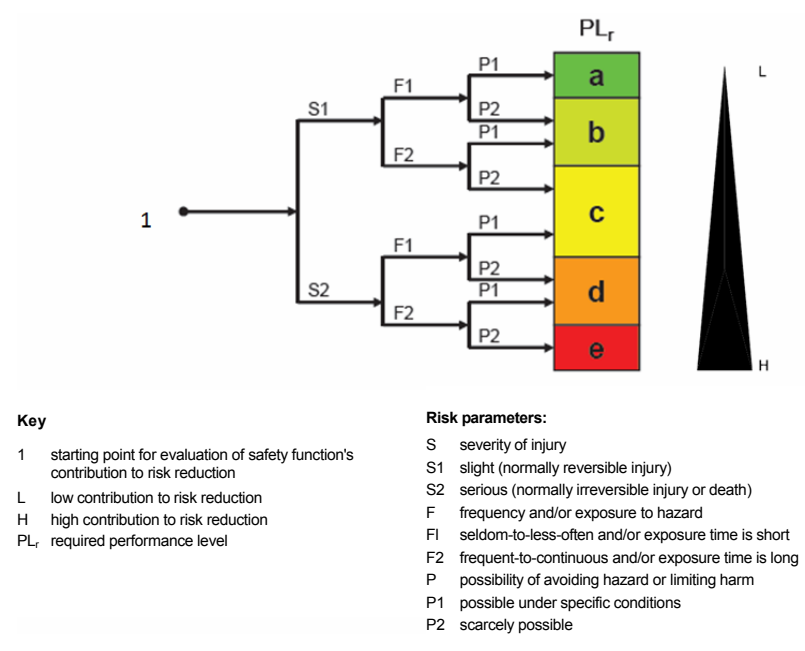

Figure 4. Risk graph for determining required $\mathrm{PL}_{\mathrm{r}}$ for safety function(EN ISO 13849-1, 2006) 
격에서는 아래 Figure 4와 같은 리스크 그래프 방식이 사용 된다.

Figure 4 와 같이 해당되는 위험과 안전 기능에 대한 필수 성능 수준 $\mathrm{PL}_{\mathrm{r}}$ (Required Performance Level)이 심각도 (Severity), 발생빈도(Frequency), 발생 가능성(Possibility)에 의해 정해지면 그에 따른 안전 기능은 최소한 해 당 성능 수준(Performance Level)의 요건들을 만족하여야 한다.

\subsection{Safety Function}

앞에서와 같이 위험성을 추정하였다면, 해당 위험성을 줄 이거나 없애기 위한 안전보호장치의 설계에 있어 그 기능을 정의하여야 한다. 이를 안전 기능이라 한다. 안전 기능이 란, 제어시스템 안전 관련 부품 (Safety-Related Parts of Control System, SRP/CS) 에 의해 수행되는 것이라 정의할 수 있다.

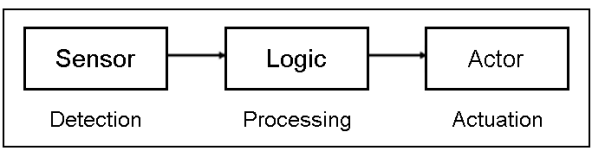

Figure 5. Safety functions are executed by SRP/CS

이러한 안전 기능을 각 개별 산업기계에 따라 결정하는데 있어, 해당 산업기계류의 제품 규격 혹은 요건을 참조하거나 위험성 평가 결과에 따라 설계자가 정의할 수 있다. 일반적 으로 사용되는 안전 기능들을 열거하면, 보호장치 동작에 따 른 안전정지 기능, 수동 리셋 기능, 기동/재시동 기능, 로컬 제어 기능, 뮤팅 기능, Hold-to-run 기능, Enabling 장치 기능, 예기치 않는 기동 방지 기능, 끼인 사람의 탈출이나 구 조 기능, 위험 에너지 격리 기능, 비상정지 기능 등을 예로 들 수 있다. 개별시스템에 각 안전 기능이 정의가 되었다면 그에 해당하는 각 $\mathrm{PL}$ 의 요구 조건들을 확인해야 한다.

\subsection{Performance Level(PL)}

$\mathrm{EN}$ ISO 13849-1 규격 3.1.23절에 따르면, $\mathrm{PL}$ (Performance Level) 을 "discrete level used to specify the ability of safety-related parts of control systems to perform a safety function under foreseeable conditions" 로 정의한다. 즉 "예측 조건 하에서 안전 기능을 수행하는 제어시스템의 안전 관련 부품의 능력을 지정하는 데 사용된 이산 레벨"을 의미한다. PL은 EN ISO 13849 규격에서 새롭
게 도입된 개념으로써 $\mathrm{EN} \mathrm{954-1} \mathrm{규격에는} \mathrm{없는} \mathrm{개념이다.}$ Figure 4에서와 같이 리스크 그래프 방식에 의해 정해진 각 안전 기능의 $\mathrm{PL}_{\mathrm{r}}$ (Required Performance Level)은 해당 안 전 기능을 구성하는 Figure 5 와 같은 $\mathrm{SRP} / \mathrm{CS}$ 의 각 블록 에 요구되는 최소 능력이나 성능을 의미한다. 여기서 요구되 는 최소 능력이나 성능은 시간당 위험 고장 확률(Average Probability of Dangerous Failure per Hour, $\mathrm{PFH}$ )의 범위 로 정의된다(Table 1). 수준 $\mathrm{e}$ 로 갈수록 시간당 평균 위험 고장 확률 값 $(\mathrm{PFH})$ 이 낮아야 하는 것을 알 수 있고, 신뢰성 이 매우 확보된 부품들의 조합이 요구된다. 결과적으로 해당 안전 기능에 대해 위험성 추정의 결과인 $\mathrm{PL}$ 수준이 정해지면, Table 1 과 같이 해당 수준에 따른 안전카테고리, $\mathrm{MTTF}_{\mathrm{d}}$, $\mathrm{DC}_{\mathrm{avg}}$ 를 확인할 수 있고, 또한 공통원인고장 $(\mathrm{CCF})$ 과 소프 트웨어 에러를 고려하여 시스템을 설계하고 적합성을 확인할 수 있다. EN ISO 13849 규격에서 새롭게 도입된 PL은 기존 EN 954-1 규격과는 달리, 기존의 안전카테고리에 $\mathrm{MTTF}_{\mathrm{d}}$, $\mathrm{DC}_{\mathrm{avg}}, \mathrm{CCF}$, 소프트웨어 검증이라는 정량적인 분류와 위험 고장 확률 이론의 도입으로 정량적인 $\mathrm{PFH}$ 값을 가지고 시 스템 설계에 있어 좀 더 세분화된 요소들을 다루고 있다.

Table 1. Performance Levels(PL) (EN ISO 13849-1, 2006)

\begin{tabular}{c|c}
\hline PL & Average probability of dangerous failure per hour $1 / \mathrm{h}$ \\
\hline $\mathrm{a}$ & $\geq 10^{-5}$ to $<10^{-4}$ \\
\hline $\mathrm{b}$ & $\geq 3 \times 10^{-6}$ to $<10^{-5}$ \\
\hline $\mathrm{c}$ & $\geq 10^{-6}$ to $<3 \times 10^{-6}$ \\
\hline $\mathrm{d}$ & $\geq 10^{-7}$ to $<10^{-6}$ \\
\hline $\mathrm{e}$ & $\geq 10^{-8}$ to $<10^{-7}$ \\
\hline
\end{tabular}

NOTE Besides the average probability of dangerous failure per hour other measures are also necessary to achieve the PL

\subsection{Safety Category}

BGIA (Institute for Occupational Safety and Health of German Social Accident Insurance)에서 1985년부터 산 업현장에서 얻어진 경험으로부터 확인된 내용으로 다양한 제어시스템들은 몇 가지 단순한 기본 안전 제어시스템으로 대표된다는 것이다. 첫째로는 단일 채널의 시스템 구성으로 진단 기능이 없는 다른 신뢰성을 가진 부품들의 조합이고, 둘째로는 단일 채널의 시스템 구성으로 진단 기능이 있는 다른 신뢰성을 가진 부품들의 조합이며, 마지막으로 두 개의 채널로 구성되며 높은 진단 기능을 가진 시스템으로 조사되 었다. 두 개 채널 초과 제어시스템은 극히 드물며, 두 개 채 널만으로도 충분히 신뢰성을 확보할 수 있기 때문에 $\mathrm{EN}$ 
954-1과 EN ISO 13849 규격에서는 두 개 채널까지만 고 려하여 지정된 시스템 구성(Designated Architecture)으로 정의한다. 따라서, 이 세 가지 구성 요소들을 바탕으로 5 가 지의 등급을 정의한다.

\section{가. 안전카테고리 B(Safety Category B)}

안전카테고리 $\mathrm{B}$ 는 앞서 언급한 첫째 요소인 단일 채널의 시스템 구성으로 진단 기능이 없는 다른 신뢰성을 가진 부 품들의 조합이다. Figure 6 과 같이 단일 채널의 구조를 가 지며, 구성 요소를 간략히 블록화하면 먼저 입력장치(I), 예 를 들어 센서류 등이 있고, 논리장치 $(\mathrm{L})$, 예를 들어 PLC (Programmable Logic Controller)나 릴레이(Relay)로 구 성된 시퀸스(Sequence) 회로 등이 있으며, 최종적으로 출 력장치 $(\mathrm{O})$, 예를 들어 전자 접촉기 (Magnetic Contactor) 등으로 구성된다. 여기서 각 $\mathrm{I}, \mathrm{L}, \mathrm{O}$ 최종 구성 요소를 블록 이라 표현한다.

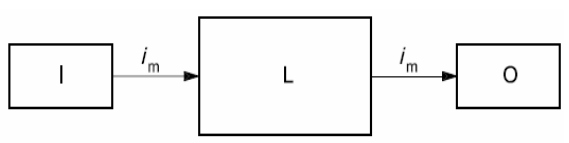

Key

$i_{\mathrm{m}}$ interconnecting means

I input device, e.g. sensor

L logic

O output device, e.g. main contactor

Figure 6. Designated architecture for category B (EN ISO 13849-1, 2006)

\section{나. 안전카테고리 1(Safety Category 1)}

안전카테고리 1은 Figure 6과 같이 안전카테고리 B와 같 은 구조의 시스템이다. 다만, 설계나 설치 시 고려해야 할 기 본 안전 원칙(Basic Safety Principles) 외에 검증된 부품 (Well-tried Components)의 사용이 추가된다. 여기서 검 증된 부품은 안전 관련 활용에서 검증이 된(Well-tried for Safety-Related Applications) 부품이라는 의미이다.

다. 안전카테고리 2(Safety Category 2)

안전카테고리 2는 안전카테고리 $\mathrm{B}$ 와 1 의 요구사항을 기 본으로 하고, Figure 7 과 같이 안전 기능의 진단(Test) 기 능이 포함된 구조를 가진다. Figure 7 에서 점선 표시된 부분 이 이상 (fault)을 감지하기 위한 진단 기능을 표현한다. 이 진단 기능은 기계가 초기 기동 시, 안전 기능 수행 전 그리 고 필요에 따라 일정한 주기로 시행된다. EN ISO 13849 규격에서는 안전카테고리 2 이상부터 진단 유효 범위(DC, Diagnostic Coverage)의 개념을 적용한다.

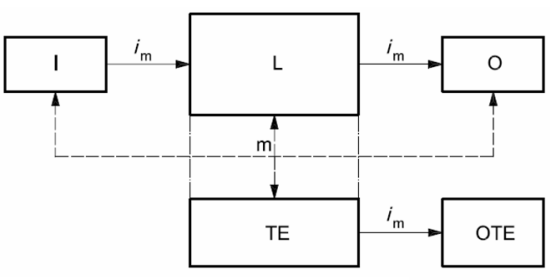

Dashed lines represent reasonably practicable fault detection.

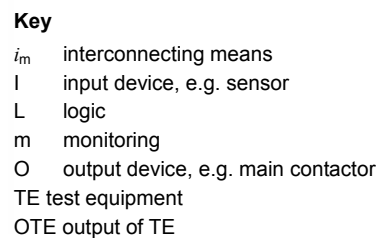

Figure 7. Designated architecture for category 2 (EN ISO 13849-1, 2006)

\section{라. 안전카테고리 3(Safety Category 3)}

안전카테고리 3 은 안전카테고리 $\mathrm{B}$ 와 1 의 요구사항을 기 본으로 하고, 단일 고장이 전체 안전 기능의 상실로 이어지 지 않게 설계되어야 한다. 따라서, 두 개의 채널을 구성하여 단일 고장이 시스템 내에서 검출되어 이중성(Redundancy) 을 구현한다. 또한, EN ISO 13849 규격에서는 안전카테고 리 2에서와 같이 $\mathrm{DC}$ 와 $\mathrm{CCF}$ 의 개념을 적용한다. 만약 소 프트웨어에 의해 제어가 된다면 그 소프트웨어도 $\mathrm{EN} \mathrm{ISO}$ 13849 규격에 의해 검증이 되어야 한다.

마. 안전카테고리 4(Safety Category 4)

안전카테고리 4 는 안전카테고리 B와 1, 2 및 3 의 요구사 항을 기본으로 하고, Figure 8과 같이 안전카테고리 3 과 같 은 시스템 구조를 가진다. 안전카테고리 3 과 다른 점은 누적

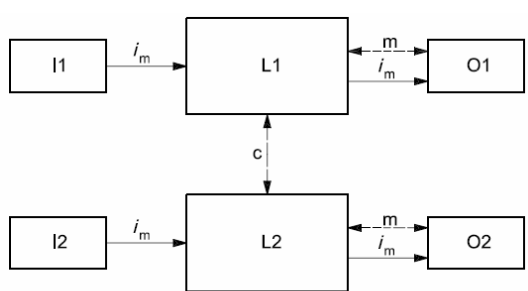

Dashed lines represent reasonably practicable fault detection.

$\begin{array}{ll}\text { Key } & \\ i_{\mathrm{m}} & \text { interconnecting means } \\ \mathrm{C} & \text { cross monitoring } \\ \mathrm{I} 1, \mathrm{I} 2 & \text { input device, e.g. sensor } \\ \mathrm{L} 1, \mathrm{~L} 2 & \text { logic } \\ \mathrm{m} & \text { monitoring } \\ \mathrm{O} 1, \mathrm{O} 2 & \text { output device, e.g. main contactor }\end{array}$

Figure 8. Designated architecture for category 3 (EN ISO 13849-1, 2006) 
된 검출되지 않은 고장들이 전체 안전 기능 상실의 원인이 되지 않아야 한다. 즉, 시스템 내에서 두 개의 고장이 일어날 경우를 판단하면 된다. 마찬가지로 EN ISO 13849 규격에서 는 안전카테고리 3 에서와 같이 $\mathrm{DC}$ 와 $\mathrm{CCF}$ 의 개념을 적용한 다. 만약 소프트웨어에 의해 제어가 된다면 그 소프트웨어 도 EN ISO 13849 규격에 의해 검증이 되어야 한다. 하지만 안전카테고리 4 의 시스템은 고장에 대한 최고의 내성을 가 져야 하므로 높은 수준의 $\mathrm{MTTF}_{\mathrm{d}}$ 와 $\mathrm{DC}_{\mathrm{avg}}$ 그리고 충분한 $\mathrm{CCF}$ 에 대한 대책이 있어야 한다.

\subsection{1 $\mathrm{MTTF}_{\mathrm{d}}($ Mean time to dangerous failure)}

$\mathrm{MTTF}_{\mathrm{d}}$ 는 위험 고장까지의 평균 시간 추정 값이다. 하지 만 통계적 의미이지 제품 자체의 보증 수명 시간이나 무고장 시간을 의미하지 않는다. 또한, $\mathrm{MTTF}_{\mathrm{d}}$ 는 시간 주기의 단위 로 년도(Year)로 표기하며, 단지 위험한 상태와 관련된 고 장만을 의미한다.

EN ISO 13849 규격에서는 FMEA (Failure Mode Effects Analysis)를 통한 복잡한 $\mathrm{MTTF}_{\mathrm{d}}$ 에 관한 계산식이 아닌 Table 2와 같이 $\mathrm{MTTF}_{\mathrm{d}}$ 의 범위를 활용해서 각 $\mathrm{PL}$ 수준 별 로 적용하는 방식을 통해 단순화한 정량적 표현을 채택하 였다.

Table 2. $\mathrm{MTTF}_{\mathrm{d}}(\mathrm{EN}$ ISO 13849-1, 2006)

\begin{tabular}{c|c}
\hline \multicolumn{2}{c}{ MTTF $_{\mathrm{d}}$} \\
\hline Denotation of each channel & Range of each channel \\
\hline Low & 3 years $\leq \mathrm{MTTF}_{\mathrm{d}}<10$ years \\
\hline Medium & 10 years $\leq \mathrm{MTTF}_{\mathrm{d}}<30$ years \\
\hline High & 30 years $\leq \mathrm{MTTF}_{\mathrm{d}} \leq 100$ years \\
\hline
\end{tabular}

\subsubsection{DC(Diagnostic Coverage)}

앞서 간단히 설명된 것과 같이 진단 유효 범위 $(\mathrm{DC}$, Diagnostic Coverage)는 EN 954-1 규격에는 없는 EN ISO 13849 규격에서 도입된 개념이다. 제어시스템의 자가 진단과 모니터링 기능의 유효성을 측정하기 위한 개념이다. 따라서, 안전카테고리 2 이상의 구조에서만 그 유효성을 측 정하기 위해 $\mathrm{DC}$ 가 사용된다. 각 $\mathrm{DC}$ 에 대한 추정은 $\mathrm{EN} \mathrm{ISO}$ 13849-1 규격 Annex E에 체크리스트가 제공된다.

\subsubsection{CCF(Common Cause Failure)}

공통원인고장 $\mathrm{CCF}$ 는 안전카테고리 2 이상의 시스템 구조 에서 필요한 $\mathrm{EN} \mathrm{ISO} 13849$ 규격에서 정의된 개념이다. 이 중화 시스템 구조 및 진단 기능이 있는 단일 채널시스템에 서도 하나 혹은 공통 원인에 따른 결함으로 인한 위험측 고
장을 $\mathrm{CCF}$ 라 한다. 단일 결함 내성시스템의 이중화 채널 구 조에서도 하나의 공통 원인으로 인해 이러한 안전 기능들이 무효화 될 수 있기 때문에 그 원인을 제거하는 것이 중요하 다. 대부분의 $\mathrm{CCF}$ 의 원인들은 물리적인 요소(고온, 전자파 장애 등) 들, 혹은 시스템적 고장(설계상 결함, 시스템 간 공 용 프로그램 결함)에 의한다. CCF는 EN ISO 13849-1 규 격 Annex F에 해당 대책 리스트를 확인하여 점수 합산한다. 안전카테고리 2 이상의 시스템은 합산 점수가 65점 이상이 어야 한다. 또한, 각 대책들을 고려할 때 제어시스템의 기술 적 특성과 환경적 요소들을 고려하여 평가해야 한다.

\section{Case studies of Comparing EN 954-1 and EN ISO 13849-1}

회로의 선택은 $\mathrm{EN} \mathrm{954-1에} \mathrm{의해} \mathrm{분류된} \mathrm{안전카테고리}$ (Safety Category) 등급 B, 1, 2, 3, 4의 회로 5 가지를 선 택하여 대표화 한다. 여기서 각 회로를 새롭게 $\mathrm{EN} \mathrm{ISO}$ 13849-1을 적용할 경우 달라지는 점을 확인하기 위함이다. 아울러 그 차이를 기술적인 관점과 경제적인 관점에서 비교 분석한다.

\subsection{A case study of safety category B}

Table 3과 같은 사례를 비교한 결과, 이전 $\mathrm{EN} \mathrm{954-1}$ 규격 적용과 달리 아래와 같은 분석 결과를 얻을 수 있었다. 다만, 예상되는 PL 수준에 따른 적용 가능한 Category, $\mathrm{MTTF}_{\mathrm{d}}, \mathrm{DC}$ 는 EN ISO 13849-1 규격에 따라, 본 연구에

Table 3. A case number 1

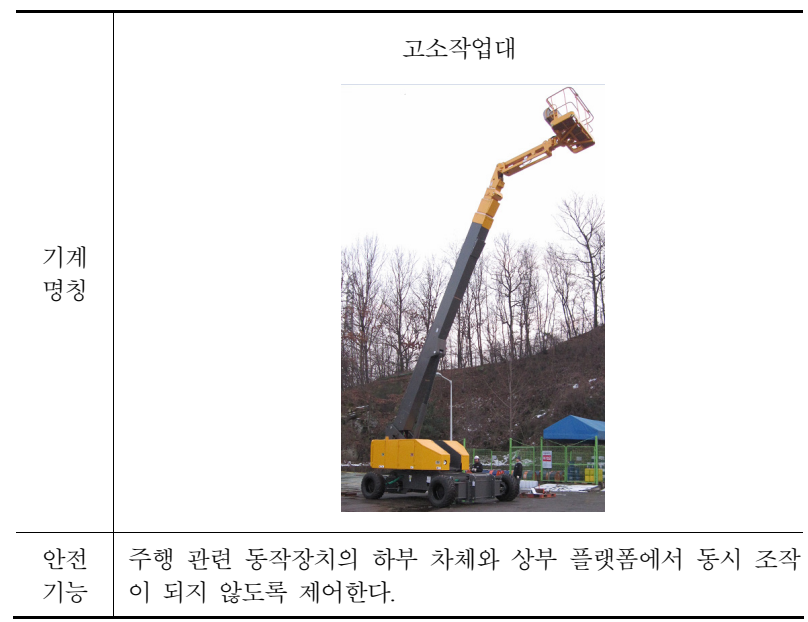


Table 3. A case number 1 (Continued)

\begin{tabular}{|c|c|c|}
\hline 구분 & EN 954-1 & EN ISO 13849-1 \\
\hline $\begin{array}{c}\text { 위험성 } \\
\text { 추정 }\end{array}$ & $\begin{array}{l}\mathrm{EN} 280 \text { 규격에 의해 해당 제 } \\
\text { 어장치는 안전카테고리 B 이 } \\
\text { 상으로 설계한다. }\end{array}$ & $\begin{array}{l}\text { 현재 EN } 280 \text { 규격이 PL 적용한 } \\
\text { 규격 내용으로 개정되지 않아, 개 } \\
\text { 별 규격을 사용한 위험성 추정 대 } \\
\text { 신 가정을 통한 위험성 추정 결과 } \\
\text { 이다. } \\
\mathrm{S} 1: \text { 동시 주행 조작에 따른 직접적 } \\
\text { 인 부상은 예상되지 않음. } \\
\mathrm{F} 2 \text { 동시 주행 조작 가능성이 빈번 } \\
\text { 할 것으로 예상. } \\
\mathrm{P} 1: \text { 차량 자체 주행 속도가 느리기 } \\
\text { 때문에 충분히 피할 수 있는 } \\
\text { 위험임. }\end{array}$ \\
\hline $\begin{array}{l}\text { 회로 } \\
\text { 구성 }\end{array}$ & $\begin{array}{l}\text { 차체 하부에 } \\
\text { 리 제어장치흘 } \\
\begin{array}{l}\text { PLVC8 } \\
\text { Controller } \\
\text { (상부) } \\
\end{array}\end{array}$ & 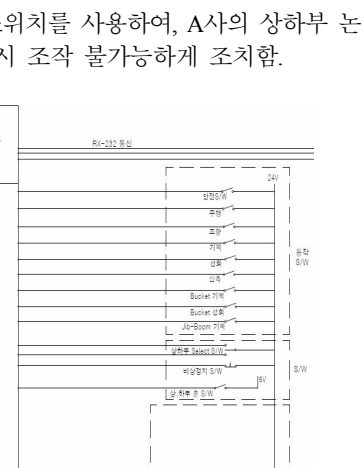 \\
\hline $\begin{array}{c}\text { 시스템 } \\
\text { 구조 }\end{array}$ & \multicolumn{2}{|c|}{$\begin{array}{r}\text { SW1: 키 형태 선택 스위치 } \\
\text { L1: 하부 논리 제어장치 } \\
\text { L2: 상부 논리 제어장치 }\end{array}$} \\
\hline $\begin{array}{l}\text { 요구 } \\
\text { 사항 }\end{array}$ & $\begin{array}{l}\text { 설계 시 부품 선택에 있어, 사 } \\
\text { 용 환경에 적합한 검증된 인증 } \\
\text { 품 사용. }\end{array}$ & $\begin{array}{l}\mathrm{PL} \mathrm{b} \text { 수준 요구사항인 중간 범위의 } \\
\operatorname{MTTF}_{\mathrm{d}}\left(10 \text { 년 } \leq \mathrm{MTTF}_{\mathrm{d}}<30 \text { 년 }\right) \text { 와 } \\
\text { 안전카테고리 B 이상일 것. } \\
\text { 소프트웨어 관리 검증 }\end{array}$ \\
\hline
\end{tabular}

서는 제조자가 쉽게 선택 가능한 최소한의 기술적 난이도와 경제적 선택 결과인 안전카테고리 $\mathrm{B}$ 와 중간 범위의 $\mathrm{MTTF}_{\mathrm{d}}$ 를 적용하였다. 앞으로의 비교 분석에서도 같은 논리로 선택 하여 적용 분석한다.

\section{가. 기술적 측면}

먼저 이전과 같은 시스템 구조를 가지기 위해 안전카테고 리 $\mathrm{B}$ 구조를 기본으로 하고, $\mathrm{PL} \mathrm{b}$ 수준 요구사항인 중간 범위의 $\operatorname{MTTF}_{\mathrm{d}}\left(10\right.$ 년 $\leq \mathrm{MTTF}_{\mathrm{d}}<30$ 년 $)$ 를 확인하기 위해 각 부품 SW1, L1, L2의 $\mathrm{MTTF}_{\mathrm{d}}$ 값을 구하여 시스템 전체 $\mathrm{MTTF}_{\mathrm{d}}$ 값을 계산 및 확인해야 한다.

일반적으로 전기기계식 스위치는 부품 제조자로부터 $\mathrm{MTTF}_{\mathrm{d}}$ 값을 참조하거나 EN ISO 13849-1 규격 부속서 $\mathrm{C}$ 에서 $\mathrm{B} 10 \mathrm{~d}_{\mathrm{d}}$ 값을 참조하여 계산할 수 있다.

하지만 논리 제어장치의 경우, 일반 표준 범용 논리 제어 장치가 아닌 고소작업대에 맞게 설계된 특수 논리 제어장치 이므로, $\mathrm{PFH}$ 나 $\mathrm{MTTF}_{\mathrm{d}}$ 값을 제조자로부터 의존해야 하므 로 선택의 폭이 제한적이다. 또한, EN 954-1 규격과 달리 ladder logic으로 구성된 SRASW 형태의 소프트웨어도 EN ISO 13849-1 규격 4.6.3절에 의해 검토되어야 한다.

\section{나. 경제적 측면}

일반적으로 논리 제어장치의 기능 안전 검증에 따른 부품 판매 단가 상승이 예상된다. 국내산 부품으로 대체하지 않는 한 가격 상승 폭을 제한할 수 있는 방법이 없다. 또한, 소 프트웨어의 규격에 따른 관리로 인한 추가 관리비용이 예상 된다.

\subsection{A case study of safety category 1}

\section{가. 기술적 측면}

시스템 구조를 안전카테고리 B 구조를 기본으로 하고, PL $\mathrm{b}$ 수준 요구사항인 중간 범위의 $\mathrm{MTTF}_{\mathrm{d}}\left(10\right.$ 년 $\leq \mathrm{MTTF}_{\mathrm{d}}<30$ 년)를 확인하기 위해 각 부품 $\mathrm{E}-\mathrm{STOP}, \mathrm{MC} 1$ 의 $\mathrm{MTTF}_{\mathrm{d}}$ 값을 구하여 시스템 전체 $\mathrm{MTTF}_{\mathrm{d}}$ 값을 계산 및 확인해야 한다.

일반적으로 널리 사용되는 부품들이기 때문에 부품 제조

Table 4. A case number 2

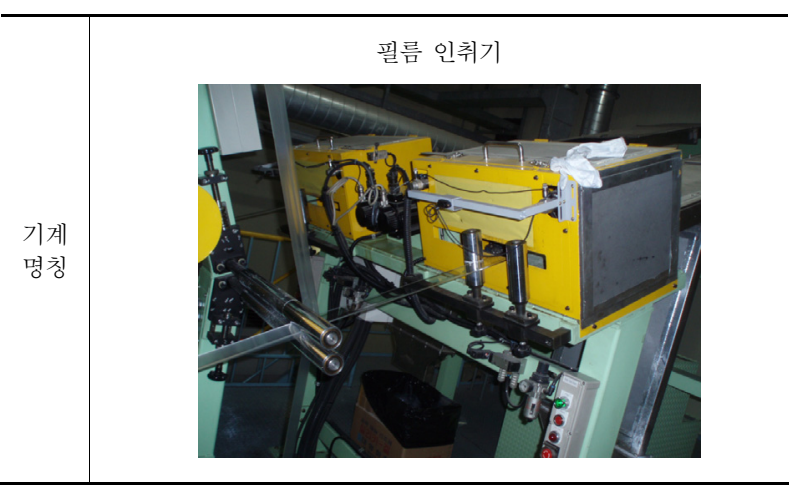


Table 4. A case number 2 (Continued)

\begin{tabular}{|c|c|c|}
\hline $\begin{array}{l}\text { 안전 } \\
\text { 기능 }\end{array}$ & \multicolumn{2}{|l|}{ 비상정지 기능 } \\
\hline 구분 & EN 954-1 & EN ISO 13849-1 \\
\hline $\begin{array}{l}\text { 위험성 } \\
\text { 추정 }\end{array}$ & $\begin{array}{l}\text { S1: 필름을 롤러에 의해 인취하 } \\
\text { 는 부분의 끼임이나 말림 위 } \\
\text { 험성 존재. 롤러의 간격에 } \\
\text { 5mm 이하로 손가락이 들어 } \\
\text { 갈 수 없는 구조이므로 아 } \\
\text { 주 경미한 찰과상 정도 예 } \\
\text { 상됨. } \\
\text { 최소 안전카테고리 }=\mathrm{S} 1 \rightarrow \text { 안 } \\
\text { 전카테고리 } 1\end{array}$ & $\begin{array}{l}\mathrm{S} 1: \text { 필름을 롤러에 의해 인취하 } \\
\text { 는 부분의 끼임이나 말림 위 } \\
\text { 험성 존재. 롤러의 간격에 } \\
5 \mathrm{~mm} \text { 이하로 손가락이 들어 } \\
\text { 갈 수 없는 구조이므로 아 } \\
\text { 주 경미한 찰과상 정도 예 } \\
\text { 상됨. } \\
\mathrm{F} 2: \text { 작접자가 상시 위치할 수 있 } \\
\text { 음. 접근 빈도 높음. } \\
\mathrm{P} 1: \text { 롤러의 간격이 좁아 손가락 } \\
\text { 이 끼일 수 없는 구조이고, } \\
\text { 롤러 회전수가 낮아 충분히 } \\
\text { 피할 수 있는 구조임. } \\
\mathrm{PL}_{\mathrm{r}}=\mathrm{S} 1+\mathrm{F} 2+\mathrm{P} 1 \rightarrow \mathrm{b}\end{array}$ \\
\hline $\begin{array}{l}\text { 회로 } \\
\text { 구성 }\end{array}$ & $\begin{array}{l}\text { 비상정지 스위치(E-STOP)를 누 } \\
\text { 구동코일(MC1)이 전원을 잃게 } \\
\text { 러 구동 모터를 정지 시킨다. }\end{array}$ & 레게 되면, 전기기계 접촉기의 보조 \\
\hline $\begin{array}{l}\text { 시스템 } \\
\text { 구조 }\end{array}$ & $\begin{array}{l}\text { E-STOP: 비 } \\
\text { MC1: 전 }\end{array}$ & 상스위치 \\
\hline $\begin{array}{l}\text { 요구 } \\
\text { 사항 }\end{array}$ & $\begin{array}{l}\text { 설계 시 부품 선택에 있어, 사 } \\
\text { 용 환경에 적합한 검증된 인증 } \\
\text { 품 사용. }\end{array}$ & $\begin{array}{l}\mathrm{PL} \mathrm{b} \text { 수준 요구사항인 중간 범위 } \\
\text { 의 } \mathrm{MTTF}_{\mathrm{d}}\left(10 \text { 년 } \leq \mathrm{MTTF}_{\mathrm{d}}<30 \text { 년) }\right. \\
\text { 와 안전카테고리 } \mathrm{B} \text { 이상일 것. }\end{array}$ \\
\hline
\end{tabular}

자로부터 $\mathrm{MTTF}_{\mathrm{d}}$ 값을 참조하거나 EN ISO 13849-1 규 격 부속서 $\mathrm{C}$ 에서 $\mathrm{B} 10_{\mathrm{d}}$ 값을 참조하여 계산할 수 있다.

\section{나. 경제적 측면}

Table 4 사례의 경우 $\mathrm{MTTF}_{\mathrm{d}}$ 계산이라는 기술적 난이도의 추가를 제외하고는 경제적인 측면에서는 크게 달라질 것이 없다. 다만 전기기계식 부품인 $\mathrm{E}-\mathrm{STOP}$ 과 $\mathrm{MC1}$ 의 경우, EN ISO 13849-1 규격의 부속서 C에서 $\mathrm{B} 10 \mathrm{~d}_{\mathrm{d}}$ 값을 활용 하여 $\mathrm{MTTF}_{\mathrm{d}}$ 를 계산할 수 있지만 가능한 부품 제조자의 환 경에 따른 $\mathrm{B} 1 \mathrm{O}_{\mathrm{d}}$ 값이 우선이므로, 기계 제조자 입장에서는 현재 변화된 규정이 잘 반영된 유럽산 부품이 사용 대체될 수도 있다. 대부분의 유럽산 부품이 국내산 부품에 비해 가 격이 높은 편이다.

\subsection{A case study of safety category 2}

\section{가. 기술적 측면}

EN 954-1 규격에 따르면 위험성 추정에 따라 안전카테 고리 2 이상이 요구되어지나, EN ISO 13849-1 규격에 따 르면 최소 안전카테고리 1 과 높은 범위의 $\mathrm{MTTF}_{\mathrm{d}}$ 부품으로 시스템을 구성할 수 있다. 진단 기능이 추가되지 않으므로 기술적 난이도는 EN ISO 13849-1 규격 적용으로 완화되 는 것으로 분석된다. 물론 더 상위의 기술을 택할 수도 있겠 지만, 비용 대비 위험성 감소라는 균형점은 각 제조자의 판 단이므로 위험성 추정에 따른 최소한의 설계가 오류나 잘못 된 것으로 판단할 근거는 없다. 결과적으로 이 사례에서는 EN ISO 13849-1 규격 적용으로 시스템 구조가 안전카테 고리 2에서 안전카테고리 1 이상으로 기술적 난이도가 한 단계 낮은 구조적 요건을 선택할 수 있다. 대부분의 전기기 계식 부품의 경우 높은 범위의 $\mathrm{MTTF}_{\mathrm{d}}$ 기대 혹은 선정함에 있어 어려움은 없을 것으로 추정한다.

Table 5. A case number 3

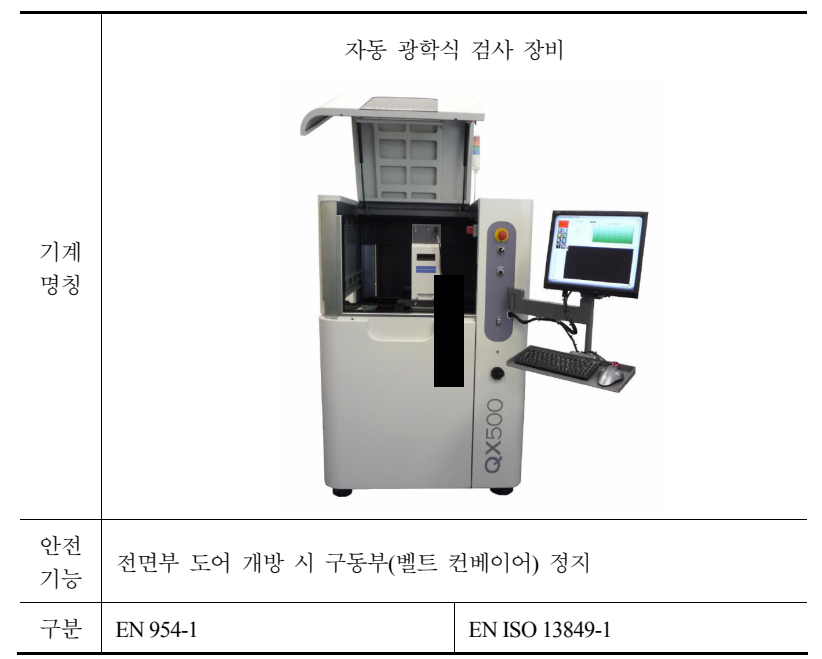




\section{Table 5. A case number 3 (Continued)}

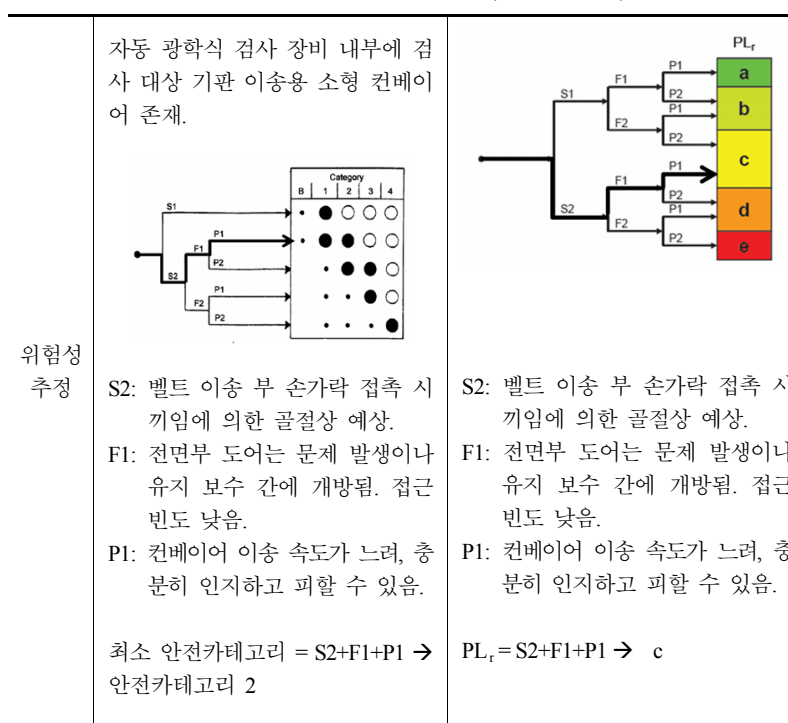

전면부 도어에 Tongue 형식의 도어 인터록 스위치(S3)를 부착하여, 도어 개방 시 안전릴레이(K1)의 입력 측 $\mathrm{S} 3$ 접점이 개방되어, 출력 측 전기기 계식 릴레이(K1)을 개방한다. K1은 직류전원을 사용하는 구동부 드라이 버 전원을 차단한다. 또한 도면 상에는 표기되어 있지 않지만, 안전릴레 이(K1)의 내부 모니터링 기능에 의해 입력(S3)과 출력(K1)을 일정한 주 기로 진단한다.

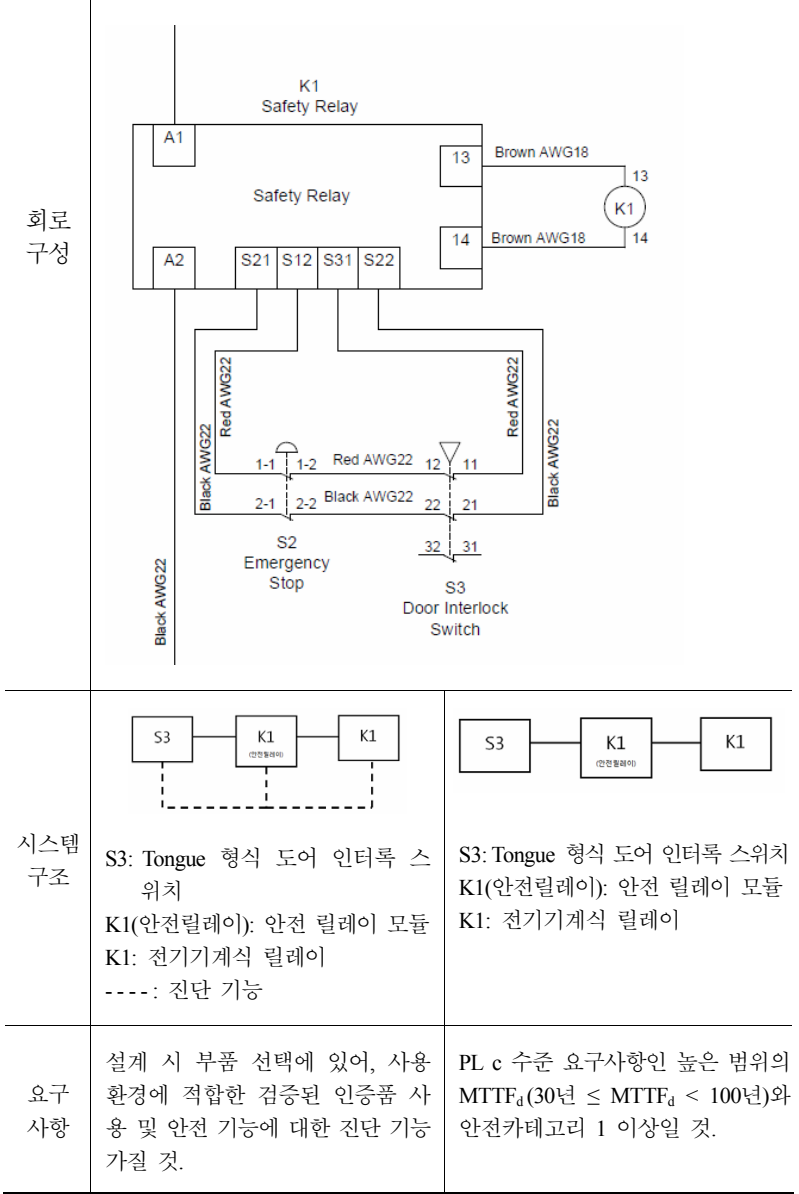

\section{나. 경제적 측면}

앞서 설명한 기술적 측면의 결과와 같이 안전카테고리 2 를 만족하기 위한 진단 기능이 필요하지 않음으로 대략 개당 50 만원에서 100 만원 가량의 안전릴레이 모듈을 사용할 필 요가 없다. 이 전 EN 954-1 규격에서는 EN ISO 13849-1 규격과 같이 정량적인 선택이 불가해서 제조자 입장에서 논 쟁의 소지를 피하기 위해 다소 과잉 설계를 통한 고가의 안 전릴레이 모듈들을 실제 그 기능을 다 사용하지 않으면서 채택한 사례가 아주 많았다. Table 5의 사례에서는 높은 범 위의 $\mathrm{MTTF}_{\mathrm{d}}$ 시스템을 위해 신뢰성 확보된 전기기계식 스 위치와 간단한 시퀸스(Sequence) 구성과 스위칭을 위한 릴 레이들만으로도 설계 요건을 만족할 수 있다.

\subsection{A case study of safety category 3}

\section{가. 기술적 측면}

이 전 $\mathrm{EN} \mathrm{954-1} \mathrm{규격을} \mathrm{적용할} \mathrm{경우} \mathrm{위험성} \mathrm{추정} \mathrm{결과}$ 에 따라 안전카테고리 3 이상을 선택하여, 그 요구사항을 설 계에 반영하여야 했다. 안전카테고리 3에서의 요구사항은 앞 서 설명한 것과 같이 이중화 구조의 시스템에 있다. 따라서 이 전 설계에서는 두 개의 개별 입력장치(S303A, S303B) 와 두 개의 독립 채널을 가진 안전릴레이 (SR) 모듈, 두 개 의 직렬 연결된 출력장치 $(\mathrm{K} 202 \mathrm{~A}, \mathrm{~K} 202 \mathrm{~B})$ 를 사용하여 시 스템을 구성하였다. Table 6과 같이 EN ISO 13849-1 규 격을 적용할 경우, $\mathrm{PL} \mathrm{d}$ 수준이 위험성 추정으로 선택되었 고 Table 6에 따라 PL d 수준에서 요구되는 시스템 요건은 최소 안전카테고리 2와 높은 범위의 $\mathrm{MTTF}_{\mathrm{d}}$, 중간 범위의 $\mathrm{DC}_{\mathrm{avg}}$ 를 적용할 수 있다. 즉, 현재의 위험성 추정 결과가 높 은 범위의 $\mathrm{MTTF}_{\mathrm{d}}$ 와 중간 범위의 $\mathrm{DC}_{\mathrm{avg}}$ 로써 단일 채널의 진단 기능이 있는 시스템 구조로 위험성을 감소할 수 있음을 의미한다. 이 사례에 있어 회로 구성에 있어서는 EN ISO 13849-1 규격에 따른 설계가 안전카테고리 2로 가능하므

Table 6. A case number 4

기계
명칭


Table 6. A case number 4 (Continued)

\begin{tabular}{|c|c|c|}
\hline $\begin{array}{l}\text { 안전 } \\
\text { 기능 }\end{array}$ & \multicolumn{2}{|c|}{ 전면부 도어 개방 시 구동부(갠트리식 이송 삽입기) 정지 } \\
\hline 구분 & EN 954-1 & EN ISO 13849-1 \\
\hline $\begin{array}{l}\text { 위험성 } \\
\text { 추정 }\end{array}$ & $\begin{array}{l}\mathrm{S} 2 \text { 삽입기 이송에 따른 골절 } \\
\text { 및 삽입기에 의한 손가락 } \\
\text { 절단 위험성 예상. } \\
\mathrm{F} 1: \text { 전면부 도어는 문제 발생 } \\
\text { 이나 유지 보수 간에 개방 } \\
\text { 됨. 접근 빈도 낮음. } \\
\mathrm{P} 2: \text { 삽입기 이동 및 속도 빠 } \\
\text { 븜. 회피 가능성 없음. } \\
\text { 최소 안전카테고리 = } \\
\mathrm{S} 2+\mathrm{F} 1+\mathrm{P} 2 \rightarrow \\
\text { 리 } 3\end{array}$ & $\begin{array}{l}\mathrm{S} 2 \text { : 삽입기 이송에 따른 골절 및 } \\
\text { 삽입기에 의한 손가락 절단 } \\
\text { 위험성 예상. } \\
\mathrm{F} 1: \text { 전면부 도어는 문제 발생이 } \\
\text { 나 유지 보수 간에 개방됨. } \\
\text { 접근 빈도 낮음. } \\
\mathrm{P} 2 \text { 삽입기 이동 및 속도 빠름. } \\
\text { 회피 가능성 없음. } \\
\mathrm{PL}_{\mathrm{r}}=\mathrm{S} 2+\mathrm{F} 1+\mathrm{P} 2 \rightarrow \mathrm{d}\end{array}$ \\
\hline $\begin{array}{l}\text { 회로 } \\
\text { 구성 }\end{array}$ & 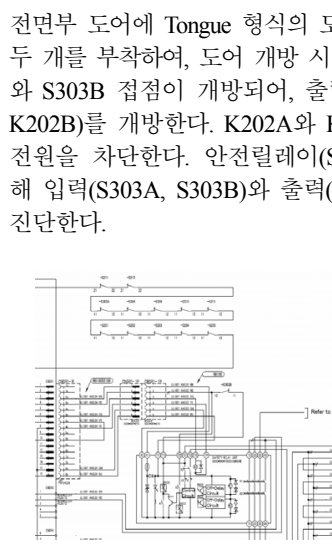 & $\begin{array}{l}\text { E어 인터록 스위치(S303A, S303B) } \\
\text { 안전릴레이(SR)의 입력 측 S303A } \\
\text { K202B은 각 구동 및 주행축 모터 } \\
\text { SR)의 내부 모니터링 기능에 의 } \\
\mathrm{K} 202 \mathrm{~A}, \mathrm{~K} 202 \mathrm{~B}) \text { 을 일정한 주기로 } \\
\end{array}$ \\
\hline $\begin{array}{c}\text { 시스템 } \\
\text { 구조 }\end{array}$ & $\begin{array}{l}\text { S303A: Tongue 형식 도어 인터 } \\
\text { 록 스위치 좌측 } \\
\text { S303B: Tongue 형식 도어 인터 } \\
\text { 록 스위치 우측 } \\
\text { SR(안전릴레이): } \\
\text { 안전 릴레이 모듈 } \\
\text { K202A } \\
\text { K202B: 전기기기계계식 접촉긱거복ㄱㄱㅣ }\end{array}$ & $\begin{array}{l}\text { S303A: Tongue 형식 도어 인터 } \\
\text { 록 스위치 좌측 } \\
\mathrm{SR}(\text { 안전릴레이): } \\
\text { 안전 릴레이 모듈 } \\
\mathrm{K} 202 \mathrm{~A} \text { : 전기기계식 접촉기 }\end{array}$ \\
\hline $\begin{array}{l}\text { 요구 } \\
\text { 사항 }\end{array}$ & $\begin{array}{l}\text { 설계 시 부품 선택에 있어, 사 } \\
\text { 용 환경에 적합한 검증된 인 } \\
\text { 증품 사용 및 이중화 회로 구 } \\
\text { 조 가질 것. }\end{array}$ & $\begin{array}{l}\mathrm{PL} \mathrm{d} \text { 수준 요구사항인 높은 범 } \\
\text { 위의 } \mathrm{MTTF}_{\mathrm{d}}\left(30 \text { 년 } \leq \mathrm{MTTF}_{\mathrm{d}}<\right. \\
100 \text { 년), 안전카테고리 } 2 \text { 와 중간 } \\
\text { 범위의 } \mathrm{DC}_{\mathrm{avg}}(90 \% \leq \mathrm{DC}<99 \%) \\
\text { 일 것. }\end{array}$ \\
\hline
\end{tabular}

로 기술적 난이도가 낮아진 편이나, EN ISO 13849-1 규격 에 따른 각 부품의 $\mathrm{MTTF}_{\mathrm{d}}$ 값을 계산하고, 특히 $\mathrm{DC}_{\mathrm{avg}}$ 에 대한 평가와 $\mathrm{CCF}$ 에 대한 평가가 따라야 하기 때문에 설계 에 있어 여러 요소들을 고려하여야 하는 복잡성을 가진다.

\section{나. 경제적 측면}

Table 6 사례의 경우 안전릴레이(SR) 모듈을 사용한 진 단 기능을 구현한다면 경제적인 측면에 있어 큰 차이가 나 지 않을 것으로 추정된다. 두 개의 개별 입력 부품 사용에서 단일 채널 구성에 따른 부품의 사용이 하나씩 줄어드는 것과 배선이 보다 간단해 진다. 만약 안전릴레이 모듈을 사용하지 않고 진단 기능을 시퀸스로 구현한다면, 어느 정도 경제적인 비용은 감소될 수도 있다.

\subsection{A case study of safety category 4}

\section{가. 기술적 측면}

이 전 $\mathrm{EN} \mathrm{954-1} \mathrm{규격을} \mathrm{적용할} \mathrm{경우} \mathrm{위험성} \mathrm{추정} \mathrm{결과}$ 에 따라 안전카테고리 4 를 선택하여, 그 요구사항을 설계에 반영하여야 했다. 안전카테고리 4 에서의 요구사항은 앞서 설 명한 것과 같이 이중화 구조의 시스템과 모니터링 기능에 있 다. 하지만, EN ISO 13849-1 규격의 적용할 경우에는 이 러한 안전카테고리 4 기준의 만족 이외에 추가적으로 사용 된 부품들이 높은 범위의 $\mathrm{MTTF}_{\mathrm{d}}$ 를 만족하는지, 시스템의 $\mathrm{DC}_{\mathrm{avg}}$ 가 높은 범위에 이르는지 또한 $\mathrm{CCF}$ 에 대한 평가가 뒤 따라야 하기 때문에 EN 954-1에 비해 훨씬 복잡한 기술적 측면을 고려하여야 한다. 앞선 사례들과는 달리 PL e 수준에 서의 요구는 선택할 수 있는 안전카테고리, $\mathrm{MTTF}_{\mathrm{d}}, \mathrm{DC}_{\mathrm{avg}}$ 의 범위가 제한적이어서 적용에 있어서도 상당한 기술적 복 잡성을 고려하여 신중히 설계 및 검토를 하여야 한다.

\section{나. 경제적 측면}

이러한 기술적 측면의 복잡성에도 불구하고 $\mathrm{EN} \mathrm{ISO}$

Table 7. A case number 5

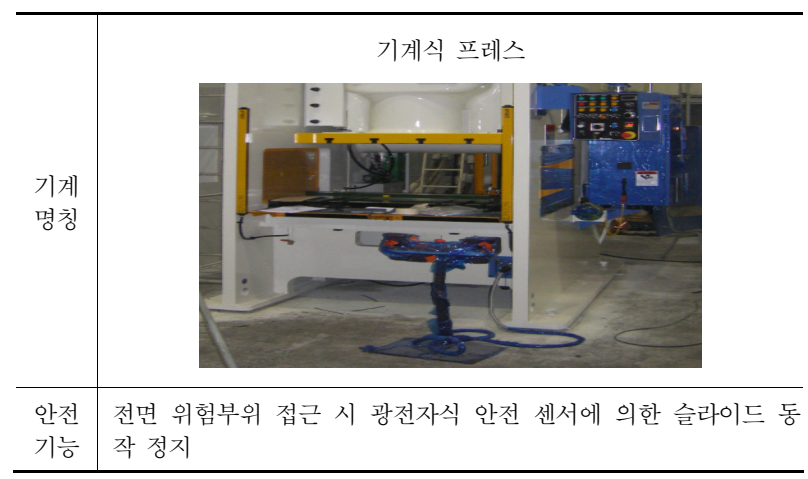


Table 7. A case number 5 (Continued)

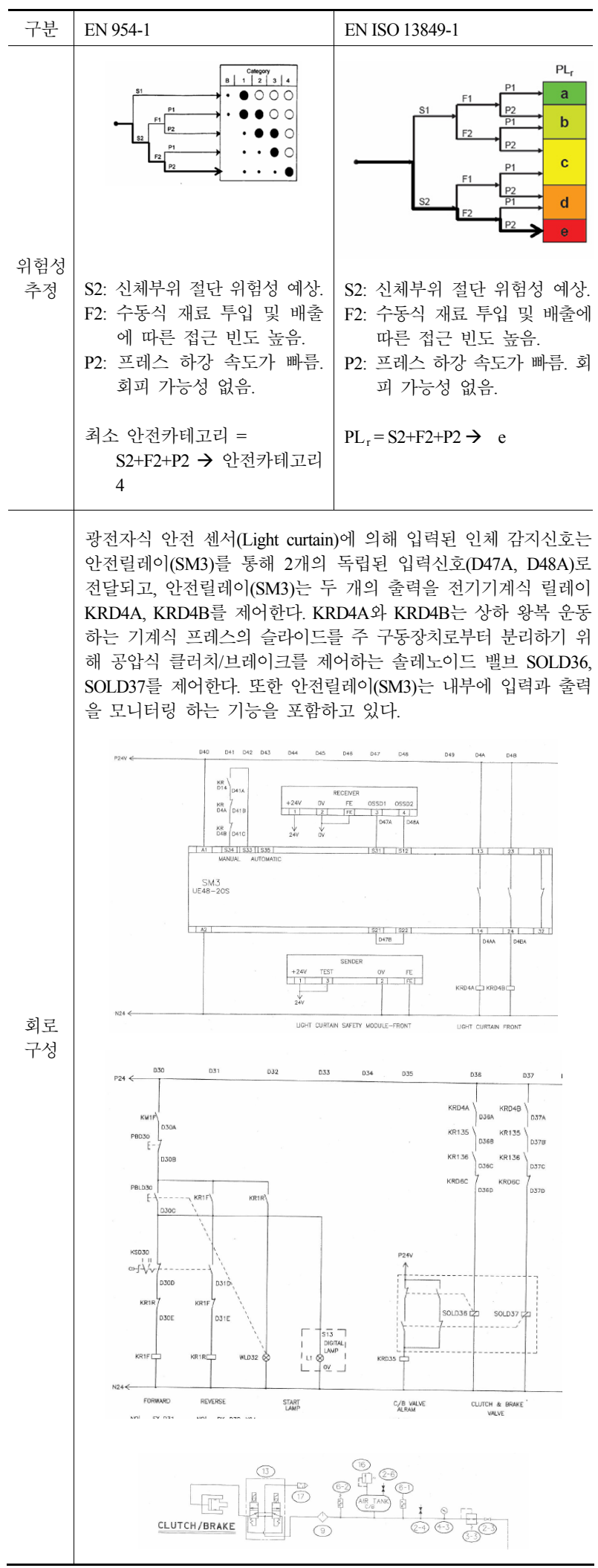

Table 7. A case number 5 (Continued)

\begin{tabular}{|c|c|c|}
\hline \multirow{2}{*}{$\begin{array}{c}\text { 시스템 } \\
\text { 구조 }\end{array}$} & \multicolumn{2}{|l|}{ Light Curtain (D47A) } \\
\hline & \multicolumn{2}{|c|}{$\begin{array}{ll}\mathrm{D} 47 \mathrm{~A}, \mathrm{D} 48 \mathrm{~A} & \text { : 광전자식 안전센서 입력 신호 } \\
\mathrm{SM} 3 & \text { : 안전릴레이 모듈 } \\
\mathrm{KRD} 4 \mathrm{~A}, \mathrm{KRD} 4 \mathrm{~B} & \text { : 전기기계식 릴레이 } \\
\text { SOLD36, SOLD37: 이중 솔레노이드 밸브 }\end{array}$} \\
\hline $\begin{array}{l}\text { 요구 } \\
\text { 사항 }\end{array}$ & $\begin{array}{l}\text { 설계 시 부품 선택에 있어, } \\
\text { 사용 환경에 적합한 검증된 } \\
\text { 인증품 사용, 이중화 회로 구 } \\
\text { 조 및 모니터링 기능 가질 것. }\end{array}$ & $\begin{array}{l}\mathrm{PL} \mathrm{e} \text { 수준 요구사항인 높은 범위의 } \\
\mathrm{MTTF}_{\mathrm{d}}\left(30 \text { 년 } \leq \mathrm{MTTF}_{\mathrm{d}}<100 \text { 년 }\right), \text { 안 } \\
\text { 전카테고리 } 4 \text { 와 높은 범위의 } \mathrm{DC}_{\mathrm{avg}} \\
(99 \% \leq \mathrm{DC}) \text { 일 것. }\end{array}$ \\
\hline
\end{tabular}

13849-1 규격에서는 이 전 EN 954-1에 비해 훨씬 정량 적인 방법에 의해 설계 및 검토가 가능하기 때문에 단순히 이중화 시스템 구조 및 모니터링 기능에 의한 설계 기준보다 명확한 검토 요소들이 주어져서 검증에 있어 빠르고 확실한 우위를 보인다. 이것은 향후 일어날 수 있는 사고 예방에 큰 도움이 되어 앞으로 발생할 수 있는 재해 사고에 따른 미래 의 경제적 손실에 있어 도움이 있을 것으로 판단한다. 하지 만 Table 7 사례와 같이 당장에 있어 EN ISO 13849-1 규격의 적용은 기술적 복잡성에 따른 설계 및 검토에 따른 인원, 시간 및 부품의 높은 신뢰성을 확보하여야 하기 때문 에 현재의 경제적 비용은 증가할 것으로 예상된다.

\section{Conclusion}

본 연구에서는 대부분의 산업기계 관련 사고들이 기계 제 어시스템의 오동작에 의한 사고 비중이 높은데, 이와 관련하 여 유럽의 오동작 방지를 위한 제어시스템 설계에 관한 관련 안전 규격인 EN 954-1과 EN ISO 13849-1에 대한 이론 적 고찰을 하였다. EN 954-1 규격은 2011년 12월 31일부 로 폐지가 되었고, $\mathrm{EN} \mathrm{ISO} \mathrm{13849-1} \mathrm{규격} \mathrm{적용이} \mathrm{강제화}$ 되었다. 이에 국내의 산업기계 관련 인증 기준을 살펴본 결 과 이러한 유럽과 국제 기준이 안전 관련 제어시스템 설계 에 관한 엄격한 표준 채택의 동향과 달리 관련 기준이 명 확하지 않은 부분이 존재함을 파악할 수 있었다. 이에 국내 산업기계 제조업계가 유럽 수출 시 겪을 수 있는 EN ISO 13849-1 규격에 대한 어려움을 해소하기 위해 국내 안전 기준을 유럽과 국제 기준과 동일하게 시스템과 관련 기준들 의 정비가 시급히 필요해 보인다.

또한, 앞서 서론에서 밝힌 바와 같이 2013년 3월 1일부 
로 적용되는 기계류의 자율안전확인신고(산업안전보건법 제 35 조)제도가 시행됨에 따라 대상 기계 - 기구 등을 제조(설 치하거나 주요 구조 부분을 변경하는 경우를 포함)하거나 수입하는 자가 해당 제품의 안전에 관한 성능이 자율안전기 준에 맞는지 확인하여 반드시 위험성 평가 자료 등을 제출하 여야 하는 의무가 있다. 대표적 대상기계는 공작기계류 등인 데, 수치 제어에 의한 안전 제어장치들이 다수 존재하며 안 전 제어장치의 오동작으로 인한 산업재해의 요인은 상시 존 재한다 할 수 있다. 하지만, 현재까지 관련 안전 설계제작기 준은 미비한 상태이고, 제조자가 스스로 위험성 평가에 의해 이러한 안전 제어시스템의 오동작에 의한 위험성을 평가하 여 최소화하거나 제거하기 위한 활동을 하기란 쉽지 않을 것으로 보인다. 따라서 국내에서도 시급히 관련 기준을 연구 하고 적용에 대한 검토가 이루어져야 할 것이다. 그러나, 하 나의 기준을 바꾸거나 추가하는 것에 국한하지 않고, 제도와 시스템을 선진화하고 정부기관, 국내 인증기관, 관련 학회 및 제조자를 중심으로 국내 실정에 맞게 실질적으로 운영이 될 수 있도록 해야 할 것이다. 이를 통해 많은 정보와 교육 그 리고 엄격한 기준의 이해도를 돕기 위한 일련의 노력들이 산업 전반에 긍정적인 영향을 미쳐 그 동안 산업기계 제조자 가 느껴 왔던 해외의 기술장벽들을 넘을 수 있게 도와주고 아울러 국내의 산업기계 관련 안전 사고를 선진화된 기준을 통해 관리될 수 있도록 하여야겠다. 또한, $\mathrm{EN} \mathrm{954-1과} \mathrm{EN}$ ISO 13849-1 규격을 10여년 동안 현장에서 검사 및 평가 를 했던 사례를 통해 향후 EN ISO 13849-1 규격을 적용 했을 경우 실질적인 기술적 경제적 장단점을 비교하여 관련 업계의 대응에 도움을 주고자 하였다. 낮은 범위의 안전카테 고리 B에서 1까지는 EN ISO 13849-1 규격이 적용이 기 술적인 구현의 다소 어려움과 경제적인 원가 상승이 될 수 있으나, 안전카테고리 2에서 4까지의 EN ISO 13849-1 규 격의 적용은 위험성 평가 결과에 따라 차이가 있을 수는 있 으나, 기존의 EN 954-1 규격의 적용과 달리 회로 설계에 있어 높은 수준의 위험 평균고장시간 값을 가진 부품의 사용 으로 회로의 단순화를 이룰 수 있어 기술적 경제적 장점들이 분명 존재하고 있다. 그리고 이전 $\mathrm{EN} \mathrm{954-1} \mathrm{규격과} \mathrm{달리}$ EN ISO 13849-1 규격은 기준 적용에 있어 정량적인 방 법들이 사용되어 이 전과 달리 적용의 모호함이 많이 개선 되었다.

이처럼 향후 관련 국제적 안전 규격들은 자유무역협정 (Free Trade Agreement, FTA)에서도 더욱 강화될 것으 로 판단된다. 본 연구를 토대로 산업기계 관련 안전 제어시 스템 설계와 관련된 EN ISO 13849-1 규격에 대한 국내 대응에 관한 연구가 활성화되고, 관련 정부기관, 학회(연구 대학), 제조자가 중심이 되어 국제 기준에 관한 대응뿐만 아 니라 국내 산업재해와 관련하여서도 하나의 중요한 안전 기
준으로 적용되었으면 한다.

\section{Acknowledgements}

This work was supported by the Dong-A University research fund.

\section{References}

British Standard, Safety of machinery - Safety-related parts of contro systems - Part 1: General principles for design (Standard No. BS EN 954-1:1997), BSI,UK ,1997.

European Commission Home Page, http://ec.europa.eu/enterprise/policies/ european-standards/documents/harmonised-standards-legislation/listreferences/machinery/(retrieved April 19, 2012.)

European Commission Home Page, http://ec.europa.eu/enterprise/sectors/ mechanical/documents/legislation/machinery/(retrieved April 19, 2012.)

Ministry of Employment and Labor, "Korean Industrial Safety and Health Act", 2012

Marek Dźwiarek, An Analysis of Accidents Caused by Improper Functioning of Machine Control Systems, JOSE, Vol. 10, No. 2, pp. 129-136, pp. 134-135, 2004.

IEC 61508 Homepage, http://www.61508.org (retrieved, April 19, 2012)

International Standard, Safety of machinery - Safety-related parts of control systems - Part 1: General principles for design (Standard No. ISO 13849-1:2006), ISO, Switzerland, 2006.

\section{Author listings}

Tae-Ho Kim: thkim@green-safety.co.kr

Highest degree: MS, Department of Industrial \$ Management Systems Engineering, Graduate School of Industry and Information, Dong-A University

Position title: President

Areas of interest: Risk Management, Human factors in machinery design. Safety management 
Hong-Ki Kim: hkkim@kyonggi.ac.kr

Highest degree: Ph.D, Department of Industrial Engineering, Texas Tech University

Position title: Professor, Department of Industrial and Management

Engineering, Kyonggi University

Areas of interest: Biomechanics, Work Physiology, Psychophysics, MMH,WMSD, Product development and design

Hoon Yong Yoon: yhyoon@dau.ac.kr

Highest degree: Ph.D, Department of Industrial Engineering, Texas Tech University

Position title: Professor, Department of Industrial and Management Systems Engineering, Dong-A University

Areas of interest: Industrial Ergonomics, Psychophysics, MMH, Work

Physiology, Product design and Evaluation
Date Received : 2013-03-13

Date Revised :2013-04-03

Date Accepted : 2013-04-09 